\title{
Regime de Partilha do Pré-SAL e a Regulação da Atividade Petrolífera ${ }^{\top}$
}

\author{
Regulation and legal discussions concerning the Brazilian "pre-salt" oil \\ and gas sector
}

\author{
Benevenuto Silva dos Santos ${ }^{2}$ \\ Flavio Edmundo Novaes Hegenberg ${ }^{3}$
}

1 Este texto trata do regime de partilha. Este é o foco do trabalho não por considerar tal regime como "ideal" ou "melhor" ... mas simplesmente como tema de estudo. Outro interessante tema de estudo, que poderá ser tratado em outro texto, é o do regime de concessão.

2 Advogado, Mestre em "Direito e Economia" (Universidade Gama Filho - UGF, Rio de Janeiro); Professor do curso de Direito do Centro Universitário de Volta Redonda - UniFOA. benevenutofss@uol.com.br

3 Geólogo, Mestre em "Administração e Política de Recursos Minerais" (Universidade Estadual de Campinas - UNICAMP) e "PhD in Business" (University of Leeds, Inglaterra). Professor de Economia Política, História Econômica Geral e Desenvolvimento Econômico do Brasil - UniFOA. flavio.leeds@gmail.com

\section{Resumo}

Uma das inovações do modelo de reforma do Estado, inaugurado (e descontinuado, posteriormente) no governo 1995/1998, a reestruturação do modelo autárquico deu surgimento às denominadas agências reguladoras . Essas entidades, diga-se, estão sujeitas a um vínculo com a administração central em questões de resultados (e não de funcionamento orgânico). Essa criatividade na administração pública atende ao princípio da eficiência, que busca dar resultados aos cidadãos e aos usuários dos serviços públicos. A Administração Indireta, para tanto, sujeita ao manto dos princípios da tutela e controle e da especialidade, também pode ser organizada sob as formas: empresarial e fundacional (i.e., como fundação). O sistema regulatório da indústria petrolífera busca atender uma lógica estatal e de mercado, ainda que a maior empresa estatal do Brasil (a PETROBRAS) seja objeto de constante interferência governamental (de fato). Em primeiro plano houve a criação da Agência Nacional do Petróleo (ANP). Após início da extração do pré-sal, a Lei 12.351, de 22/12/2010, adotou a coexistência de dois modelos: os sistemas de (a) concessão e de (b) partilha (na exploração do petróleo); modificando parcialmente o marco regulatório do modelo de exploração do citado recurso energético. Para a gestão do sistema de partilha, aplicado ao pré-sal, o Poder Público Federal (PPF) instituiu uma empresa estatal, a Empresa de Administração do Petróleo e Gás Natural S.A. (PPSA; também chamada Pré-Sal Petróleo S.A. ), posto que a relação jurídica referente à exploração se alterou. Essa situação, de certa forma, pode levar à instabilidade de atores envolvidos na gestão da produção no setor regulado e no mercado. Neste estudo discutiremos o papel atual desses agentes envolvidos, abrangendo as atribuições e as interações de órgãos e entidades administrativas.

\section{Palavras-chave}

PETROBRAS; indústria de petróleo e gás; legislação e regulação.

\begin{abstract}
Considering innovations regarding State reform and regulation (which in Brazil were inaugurated in 1995 and discontinued in 1998), and with modification to the autarchic legal model, main changes included the creation of Regulatory Agencies. These new institutional arrangements are subject to central government coordination when dealing with results (not regarding its direct management). This public management creativity is supposedly relevant in terms of the "efficiency principle" (dealing with end results for citizens and public service users). As things stand, the Indirect Administration, subject to certain principles, broad controls and specificities, may also be organized as an enterprise or as a foundation. The oil industry regulatory system attempts to organize itself under a State-market framework (even if there is a great deal of de facto government interference in companies where the Brazilian State, and Government, is a major player). As a first layer of regulation (and interference) we must consider the National Petroleum Agency (ANP). Following extraction from the "pre-salt" in Brazil, Law number 12.351 (issued on the $22^{\text {nd }}$ December, 2010), it was adopted the coexistence of two competing models for oil and gas exploitation: (a) permission (concessão), and (b) parceling ("partilha"). This implied a partial modification of the regulatory benchmark, regarding the exploitation of oil and gas in Brazil. With respect to the parceling system (applied to "pre-salt" deposits), the Federal Government (PPF) created the state-owned enterprise "Presalt Administration Company" (PPSA), as a result of changes to the legal framework (as mentioned previously). This situation, as argued, may create instability for the participants involved in production management (both in the regulated sector and in market relations). This paper discusses the role of agents involved in the process and also the duties and interactions between state and private entities.
\end{abstract}

\section{Keywords}

PETROBRAS; oil \& gas industry; legislation and regulation.

\section{Como você deve citar?}

SANTOS, Benevenuto; HEGENBERG, Flávio. Edmundo Novaes. Regime de Partilha do Pré-SAL e a Regulação da Atividade Petrolífera. Cadernos UniFOA, Volta Redonda, n. 27, p. 59-73, abr. 2015. 


\section{INTRODUÇÃO}

O novo regime de partilha na exploração do petróleo, iniciado a partir da extração do pré-sal, tornou a PETROBRAS a principal exploradora das áreas que serão objeto de licitação, iniciando-se com a extração de "Libra (denominação de uma região de exploração) ${ }^{4}$, cujo consórcio tornou-se parceiro da citada Estatal.

Em decorrência desse novo sistema adotado pela Lei 12.351, de 22/12/2010, o leilão promovido não resultou em sucesso, pois grandes empresas não se mostraram interessadas, ou, por outro lado, mostrou êxito, pois, mesmo com uma interferência maior do Estado no empreendimento, houve empresas internacionais que apostaram no sucesso desse novo modelo, em um instante em que a PETROBRAS tem sido objeto de crítica no cenário internacional, muito mais pela interferência do Governo, devido ao baixo preço, ou pela plena estatização (de uma política que deveria seguir o mercado). (...) não considerando aqui as questões ligadas a possíveis casos de corrupção (amplamente divulgados na mídia).

0 que se pretende neste estudo é a discussão em torno do regime de exploração adotado pela Constituição e pela Lei 12.351/10, bem como o papel a ser desempenhado pelos novos atores. Para tanto, analisaremos também a Lei 9.478/97, que não foi revogada, e suas implicações na órbita constitucional e compatibilidade com os princípios que norteiam a Administração Pública e a intervenção do Estado na economia.

\section{A REGULAÇÃO DA ECONOMIA COMO FORMA DE INTERVENÇÃO DO ESTADO NA ECONOMIA}

0 artigo 173 da Constituição Federal (de 1988) permite ao Estado brasileiro adotar medidas administrativas, desde que previstas em lei, para interferir beneficamente na economia, seja evitando a concentração de poder econômico, seja utilizando diretamente suas empresas estatais para atuar em setores estratégicos. Para tanto, o mesmo dispositivo prevê que o desempenho de atividade empresarial pelo Estado somente dar-se-á quando imperativo para a segurança nacional ou relevante para o interesse público. É o que nos permite agora considerar o princípio da subsidiariedade, em que tal critério é aventado nas relações entre a atuação estatal e a iniciativa privada, fixando a distribuição de suas ações, sendo a ação estatal residual (MEDAUAR, 2003, p. 245). 0 grau de intervenção do Estado, por consequência, define um modelo regulatório que será determinante para a atração de investimentos nacionais ou estrangeiros.

A exploração do petróleo no Brasil é resultado de um modelo intervencionista, com características de países em desenvolvimento ("Modelo Periférico"). Quando comparamos alguns pontos relevantes, podemos perceber, por exemplo, que no modelo periférico temos um jogo de forças "dessimétrico" (tendo o Estado como tutelar: apresentando um forte controle político e decisório representado pela ação de um "governo forte"). Isso significa uma forte defesa dos interesses de Governo, não necessariamente representando a defesa do "Public Interest" (como no caso americano), ou a defesa do "Welfare State" (como no caso europeu).

Pensando sobre regulação cabem aqui alguns comentários advindos de Musacchio \& Lazzarini (2015, páginas 107, 132): Sob o comando do presidente Vargas, o Estado brasileiro se tornou empreendedor ostensivo e se aventurou em vários setores como fundador de grandes empreendimentos (entre eles a PETROBRAS). De 1953 até a década de 1970 a PETROBRAS atuava principalmente como empresa comercial, importando petróleo bruto e produtos refinados. Como parte das políticas de privatização e de

4 Grande campo petrolífero em águas profundas da costa oceânica brasileira. 
liberalização da década de 1990, o presidente Fernando Henrique Cardoso (FHC) liberalizou a indústria petrolífera em 1997. Naquele ano, promulgou a "Lei do Petróleo" [Lei número 9478 de 6 de agosto de 1997], que extinguiu o monopólio do petróleo pela PETROBRAS e abriu os mercados de petróleo e gás no Brasil para empresas estrangeiras e para a concorrência no exterior. Cardoso também eliminou as restrições que proibiam estrangeiros possuírem ações da PETROBRAS. Finalmente, em agosto de 2000, o governo FHC registrou as ações da PETROBRAS na Bolsa de Valores de Nova York.

É relevante lembrar que: "No Brasil, a Agência Nacional do Petróleo (ANP) é relativamente fraca e muito influenciada pelo governo. Além disso, ficou com a reputação manchada desde quando alguns de seus executivos foram pilhados extorquindo empresas privadas. Em consequência, o presidente do Brasil e o ministro das Minas e Energia são os "reguladores" de fato da PETROBRAS" (Musacchio \& Lazzarini, 2015, p. 218).

\section{O SISTEMA REGULATÓRIO PARA O SETOR DE PETRÓLEO: AGENTES ENVOLVIDOS.}

A atuação do Estado na economia petrolífera se inicia com a criação da Frota Nacional de Petróleo (FRONAPE; criada em 1950), durante do Governo Presidente Dutra (presidente de 1946 a 1951). Competia a essa empresa a compra de petróleo no mercado internacional, cujo preço era bastante atrativo, se comparado com o custo de parte da produção brasileira (exportações).

A criação de empresa estatal PETROBRAS, responsável pela (a) exploração (na época bastante reduzida), (b) produção e (c) transporte do petróleo, foi executada por intermédio da Lei federal 2.004 (de 03 de outubro de 1953); como resultado vitorioso de uma campanha pelo movimento "O Petróleo é Nosso". Isso ocorreu em pleno Governo Vargas, como consequência e desdobramento da descoberta de petróleo em Lobato, na Bahia, em 1939.

Não havia, naquele momento, previsão do monopólio da exploração de atividade do petróleo; tampouco aspectos regulatórios para o setor. Isso, mesmo a despeito da existência do Conselho Nacional do Petróleo (CNP; criado pelo Decreto-Lei número 395 em 29 de abril de 1938), autarquia reguladora do setor à época. Durante a década de 70 (de 1973-74 e 1979-80), com mudança do cenário internacional, a partir das crises do petróleo (elevando sobremaneira os preços do barril de petróleo no mercado internacional), a PETROBRAS é levada a repensar seu modelo de dependência da extração internacional. Já em 1975, contratos de risco foram firmados para fomentar a exploração e a pesquisa, a fim de diminuir a vulnerabilidade do Brasil diante dessa crise.

Observe-se, o "sistema regulatório brasileiro"5 - que sempre operou a partir da lógica da estatal exploradora da atividade pública, ou seja, das grandes "holdings" de "setores estratégicos", a saber, PETROBRAS, ELETROBRAS e TELEBRAS, atuando (respectivamente) nos setores de petróleo, energia e telecomunicações (com diversas empresas subsidiárias) - é quem possuía todas as informações sobres os citados setores. As autarquias que fiscalizariam os setores, a saber, Conselho Nacional de Petróleo (CNP), Departamento Nacional de Energia Elétrica (DNEE), e Departamento Nacional de Telecomunicações (DNT), exerciam, timidamente, qualquer papel de controle.

Em decorrência da aplicação do princípio da especialidade para criação de entidades na Administração Indireta (PIETRO, 2006, p. 86), pode-se considerar que a PETROBRAS possui finalidades

\footnotetext{
5 Estamos considerando aqui, e.g., as Agências Reguladoras, o Banco Central, o Instituto Nacional de Metrologia, Qualidade e Tecnologia (Inmetro).
} 
empresariais, recebendo da lei que autorizou a sua criação, autonomia para celebrar contratos visando seu objeto estatutário.

A PETROBRAS, portanto, tem passado por transformações, já há quase duas décadas, pensando tornar-se uma empresa do setor de energia (uma visão mais abrangente do que simplesmente uma empresa do setor de petróleo). Isso significa, fica óbvio, que seu mercado não mais se restringe ao petróleo. A empresa tem atuado na exploração de gás e também no setor de biocombustíveis. A última reestruturação foi determinada pela Lei 9.478/97, que previa a criação de duas subsidiárias da PETROBRÁS, uma na área de transporte e outra na produção de gás. Particularmente, neste texto, não se fez referência à exploração de biocombustíveis.

\section{O MONOPÓLIO DA EXPLORAÇÃO ECONÔMICA DO PETRÓLEO.}

As atividades econômicas decorrentes do petróleo foram normatizadas no art. 177, da Constituição Federal de 1988. Naquela época, a despeito da visão democrática e "razoavelmente liberal" (levando em conta que estamos tratando de uma constituição elaborada ainda no período "bipolar" característico do período pré-queda do muro de Berlim; período ainda influenciado por ideias soviéticas e socialistas), o monopólio da exploração das atividades ligadas à exploração de petróleo deveria estar em poder da União, por intermédio da PETROBRAS (uma visão de "governo forte" e interventor).

Posteriormente, a Emenda Constitucional 9/95 (EC 9/95) alterou a redação do dispositivo indicado, possibilitando que empresas estatais e privadas participassem da exploração, produção, transporte, importação, exportação (i.e., extração) e distribuição de petróleo, derivados e gás natural. Pelo novo contorno do dispositivo constitucional, seria criado um órgão ${ }^{6}$ regulador de tais atividades. A Lei 9.478/97 criou, assim, a Agência Nacional do Petróleo (ANP), sucessora do já citado CNP, autarquia federal vinculada ao Ministério das Minas e Energia (MME).

Deve-se frisar que a exploração do petróleo não se caracteriza como serviço público, sendo, entretanto, atividade econômica monopolizada, que somente poderia ser exercida com a anuência do Estado. ${ }^{7}$ Ainda que não o fosse, a matéria-prima do qual se deriva o produto final do petróleo é incluída entre os bens da União, nos termos do art. 20, nos quais jazidas e demais recursos localizados em plataforma continental e zona econômica exclusiva são de domínio federal.

\section{OS NOVOS CONTORNOS DE UMA SOCIEDADE DE ECONOMIA MISTA INTERNACIONALIZADA: A PETROBRAS.}

A empresa estatal "Petróleo Brasileiro S/A" (PETROBRAS), sociedade de economia mista federal, não possui os mesmos contornos das demais empresas estatais, ainda que se enquadre aos ditames do art. $5^{\circ}$ do Decreto-lei 200/67, diploma que criou um ordenamento jurídico para a organização administrativa federal. [Chamamos neste texto a PETROBRAS de "estatal" - quando na verdade é uma "empresa mista" - para evidenciar sua origem histórica, e suas práticas operacionais, fortemente dependentes dos vários governos federais ao longo da história do Estado brasileiro].

\footnotetext{
6 A expressão órgão tem o significado de uma organização vinculada à Administração Pública, não necessariamente uma desconcentração. A opção pela autarquização segue o modelo de estrutura do Decreto-lei 200/67, recepcionado pela Constituição Federal de 88, em seu art. 37, XIX.

7 A distribuição de gás canalizado, atividade vinculada diretamente à exploração de petróleo, é definida como serviço público de competência exclusivamente estadual, expressa no art. 25, § 2 , Constituição Federal.
} 
Boa parte de seu capital está internacionalizado, por intermédio de ações negociadas na Bolsa de Valores de Nova York (NYSE ou "New York Stock Exchange"). Esse processo de internacionalização de seu capital acompanha a tendência de penetração da empresa no mercado internacional de exploração do petróleo. Isso não é um atraso, mas uma prova da eficiência pontual no setor público. As tecnologias de exploração de petróleo em águas profundas são plenamente utilizadas pela PETROBRAS, algo difundido de forma ampla nos meios de comunicação (muitas vezes de forma errônea, dando a entender que as tecnologias são nacionais - quando não são, pois são normalmente compradas de outros países; para uma visão mais tecnológica e detalhada desse assunto veja Hegenberg, 2000).

Para a exploração do pré-sal, a Lei 12.351/10 fez previsão de uma empresa estatal (pública) para gerir os contratos de exploração dessas áreas, não abordando a sua atuação na operação da exploração e produção, tendo em vista o elevado custo de investimento em depósitos mais profundos do que os atualmente explorados.

Observe-se que um dos modelos de estudo pelo Governo foi o norueguês (Gaspar \& Teixeira Jr., 2008), chamado "híbrido", em razão da convivência entre empresas privadas e empresas estatais, havendo distinção entre uma estatal para aplicar os recursos obtidos em investimentos na área e novas reservas, e outra empresa estatal que compete com empresas privadas na exploração dos blocos já existentes. ${ }^{8}$

\subsection{Regulação da atividade petrolífera}

A ANP surge num contexto de desestatização, de retirada do Estado da execução e gerenciamento das atividades econômicas. A "deslegalização", doutrina desenvolvida a partir de uma visão descentralizadora do papel regulador do Estado, busca o fortalecimento desses tipos de agentes, dotados de especialidades e qualificações necessárias para a supervisão da área para o qual foram escolhidos.

Alguns pontos devem ser comentados na implantação e na regulação do setor:

1. A necessidade de conceder o direito à exploração ou produção, envolvendo, nesse caso, 0 uso do bem público (jazida) em que se localiza a reserva petrolífera. Essa concessão para exploração é um instrumento de outorga, sendo esta utilizada sempre que houver o uso de bem público ${ }^{9}$. 0 termo outorga, na cadeia de exploração de atividade, que depende de um bem público, tem como exemplo as questões que envolvam captação de recursos naturais ${ }^{10}$. É preciso separar o domínio do bem (jazida, reserva), do seu produto; este de domínio da empresa estatal exploradora, ou mesmo da PETROBRAS.

2. Criação de uma entidade regulatória, com personalidade de direito público, assumindo as funções tipicamente estatais de supervisionar as etapas do processo de exploração, produção, industrialização e transporte do petróleo, editando normas técnicas para tais finalidades, aplicando penalidades e conciliando as partes envolvidas na relação administrativa.

8 Um fato interessante do modelo norueguês é que "o país arrecada um imposto único de 78\% sobre a produção, independentemente do preço do petróleo" (Gaspar \& Teixeira Jr., 2008, p. 26). A Noruega não cobra royalties ou bônus de assinatura, como faz o Brasil. "No Brasil, os royalties e os impostos cobrados das petrolíferas somam cerca de $50 \%$, valor muito abaixo quando se compara a outros países. Locais de menor risco de exploração podem ter tributos maiores" (de acordo com o consultor Adriano Pires, In: Gaspar \& Teixeira Jr., 2008, p. 27)

9 A concessão de uso pode-se dizer ligada à exploração e produção, pois dependem diretamente da disponibilidade de um bem público, no caso, as jazidas. As demais atividades são autorizadas, recebendo o nome de outorga ou outorga autorizada; para outros autores, esta outorga é um licenciamento, por não configurar ato precário, mas dotado de vinculação entre as partes.

10 Pode ser considerada a definição de licença para o ato administrativo que reconhece o direito de explorar petróleo, por vincular ambas as partes a critérios objetivos e conferir maior segurança jurídica ao empresário. 
3. Garantia de participações governamentais na exploração, chamados royalties, pagos no início da produção pelas empresas concessionárias federais ${ }^{11}$, termo utilizado por Carlos Ary Sunfeld (2002, pp. 385-396), para descrever as empresas privadas que atuam na exploração e produção de petróleo.

Importante também diferenciarmos a exploração, como sinônimo de pesquisa (ou prospecção), depósitos que tenham por objetivo a produção futura de petróleo, de produção, que implica a lavra (ou explotação, i.e., a retirada de recursos, transformando-os em produto).

O contexto regulatório brasileiro está rodeado de incertezas sobre a capacidade da PETROBRAS de superar a cataplexia que a atinge, com a materialização dos processos investigatórios e punitivos de crimes ocorridos recentemente, correções ostensivas na gestão interna e a escrituração precisa de prejuízos, erros, desvios e sobrevalorizações, de forma a reconquistar a confiança de investidores, acionistas, parceiros e fornecedores. (...) Estão em jogo a gestão e o direcionamento de dezenas de bilhões de reais em investimentos no setor (Prates, 2015).

\section{PODERES REGULATÓRIOS DA AGÊNCIA NACIONAL DO PETRÓLEO E A DEFINIÇÃO DAS POLÍTICAS PÚBLICAS PARA O SETOR.}

O fenômeno da "agencificação" das funções do Estado ${ }^{12}$, em setores da economia e serviços públicos, nos leva a refletir sobre o papel do Governo na definição das políticas que envolvem o setor de petróleo e que caberá à atuação administrativa da autarquia regulatória. O Plano de Reforma do Estado, idealizado pelo Ministro da Administração Federal do Governo Fernando Henrique Cardoso, Bresser Pereira, difundido na mesma época da apresentação de alguns projetos de Emenda à Constituição, dentre eles o da abertura do setor de petróleo, diferenciava o papel do agente político e do agente administrativo.

A definição de políticas públicas cabe ao Estado (compondo núcleos de diretrizes estratégicas). Nesse sentido, imaginarmos que as opções referentes à exploração de bacias geológicas (ou licitação de blocos), despidas de qualquer enfoque político, não se coaduna com a noção de governo em voga. Diferentemente, são os instrumentos de gestão administrativa dispostos em lei, ao órgão ou entidade reguladora (quais sejam):

a. coordenar o processo de escolha dos concessionários;

b. efetuar estudos técnicos de viabilidade da exploração de jazidas;

c. editar normas de conteúdo técnico (imprescindíveis à integração das etapas de industrialização).

A Lei 9.478/97 descreveu à ANP as atribuições de promover a regulação, a contratação e a fiscalização das atividades econômicas integrantes da indústria do petróleo, do gás natural e dos biocombustíveis, enquanto a Lei 12.305/2010 reafirmou o seu papel regulatório:

Art. 11. Caberá à ANP, entre outras competências definidas em lei:

I - promover estudos técnicos para subsidiar o Ministério de Minas e Energia na delimitação dos blocos que serão objeto de contrato de partilha de produção;

\footnotetext{
11 A despeito de se constituir atividade econômica monopolizada, o termo utilizado para identificar o agente privado que recebe licença ou autorização do Estado é concessionário. 
II - elaborar e submeter à aprovação do Ministério de Minas e Energia as minutas dos contratos de partilha de produção e dos editais, no caso de licitação;

III - promover as licitações previstas no inciso II do art. 8ํ desta Lei;

IV - fazer cumprir as melhores práticas da indústria do petróleo;

V - analisar e aprovar, de acordo com o disposto no inciso IV deste artigo, os planos de exploração, de avaliação e de desenvolvimento da produção, bem como os programas anuais de trabalho e de produção relativos aos contratos de partilha de produção; e

VI - regular e fiscalizar as atividades realizadas sob o regime de partilha de produção, nos termos do inciso VII do art. $8^{\circ}$ da Lei no 9.478, de 6 de agosto de 1997.

A Lei 12.305/10, entretanto, por seu art. $8^{\circ}$, destacou, no sistema de partilha, o papel do Ministério das Minas e Energia (MME) de celebrar em nome da União, os respectivos contratos, ao estabelecer que:

Art. 31. A cessão dos direitos e obrigações relativos ao contrato de partilha de produção somente poderá ocorrer mediante prévia e expressa autorização do Ministério de Minas e Energia, ouvida a ANP, observadas as seguintes condições:

I - preservação do objeto contratual e de suas condições;

II - atendimento, por parte do cessionário, dos requisitos técnicos, econômicos e jurídicos estabelecidos pelo Ministério de Minas e Energia; e

III - exercício do direito de preferência dos demais consorciados, na proporção de suas participações no consórcio.

Logo, as atribuições exercidas pelos Ministérios de Estado, como órgão que auxilia o Chefe do Poder Executivo, no planejamento e controle de políticas públicas para o setor, tenderia a não comprometer o papel do órgão ou entidade que executará tais medidas; sempre com imparcialidade e profissionalismo de quem se especializou no assunto.

Em conjunto com o planejamento governamental, medida determinada pelo art. 174, Constituição Federal, pode-se verificar várias definições possíveis para o controle exercido pelo Ministério sobre entidades administrativas indiretas, independente de qual órgão da Administração Central irá exercê-lo. ${ }^{13}$

Talvez por isso, devesse existir o nítido sentimento de escolha dos dirigentes dessas agências por critérios meritórios, evitando a contaminação da Administração Pública. A função regulatória que deriva dessa norma constitucional e da lei aplicável ao tema está eivada de discricionariedade técnica, buscando sempre a eficiência da Administração Pública. 


\subsection{A questão da autonomia regulatória do sistema brasileiro}

A estrutura governamental montada para controle de órgãos inferiores e entidades vinculadas aos Ministérios de Estado constituem uma falha de nosso modelo jurídico, principalmente se verificarmos a atuação dos Ministros amparada constitucionalmente. Desde o Decreto-lei 200/67, pouco se pensou sobre a nova estrutura administrativa da administração pública federal (ou mesmo brasileira, em todas as esferas de governo). As agências reguladoras e empresas que representam verdadeiras economias de mercado sofrem constantemente com o "modelo brasileiro".

Conforme enfatiza Peter Strauss (2004a e 2004b), a relação das agências reguladoras e comissões independentes no direito americano é diferente (se comparada ao sistema no Brasil). As agências reguladoras no Brasil são estruturadas sob a forma de autarquia, vinculada ao Ministério da respectiva área de atuação no Governo. As autoridades reguladoras americanas, ou comissões independentes de regulação, não se vinculam a qualquer Departamento Federal (denominação semelhante aos Ministérios no Brasil). Segundo Strauss (2004a, p. 17-30), o Congresso Nacional pode criar órgãos como parte de um Ministério, tal como a Administração da Segurança e Saúde no Trabalho, localizado na estrutura do Ministério do Trabalho, ou órgãos independentes, controlados por uma comissão, conhecidos como comissões reguladoras autônomas, tal como a Comissão Federal de Comunicações. Nesse raciocínio, de acordo com o autor americano: na estrutura organizacional do Governo Americano, os órgãos podem estar localizados na estrutura de um Ministério (Departamento Governamental), autoridades executivas independentes e comissões regulatórias nacionais.

A lógica e a premissa são evidentes. Se tais agências recebem delegação, por intermédio de legislação federal, para exercerem atribuições normativas (do Congresso Nacional), fiscalizatórias e de controle sobre a atividade regulada (do Poder Executivo), e quase judiciária para compor conflitos (aproximando-se do Poder Judiciário), sua autonomia não lhes permite qualquer vínculo direto com qualquer Departamento Federal.

Essa interpretação fora confirmada pela Suprema Corte Americana, quando o então Presidente Roosevelt destitui um dos membros da Federal Trade Comission, comissão independente (na estrutura do Governo dos Estados Unidos). Confirmou-se o entendimento de que as "comissions" não podiam ser vistas como braço do Executivo, posto terem sido criadas pelo Congresso Nacional, exercendo suas funções por delegação deste Poder (NUSDEO, 1995, p. 91).

Não há fonte no direito americano, contudo, que assegure um controle sobre a atuação das agências que excluam a atuação do Congresso Nacional. No sistema constitucional brasileiro, a má regulação das agências pode levar a dupla ação de invalidação de seus atos, por parte do Congresso Nacional (art. 49, X, Constituição Federal), e do Ministério a que estiver vinculada (art. 87, parágrafo único, Constituição Federal), não esquecendo a ação permanente do Presidente da República.

Da forma como se observa no direito americano, a delegação normativa técnica decorre de autonomia do Poder Legislativo. No Brasil, estando a proposta de criação de órgãos e entidades da administração pública federal concentradas na figura do Chefe do Poder Executivo (e seu poder de fazer cumprir a lei), percebe-se que a regulação é uma transferência de atribuição proporcionada pelo Poder Executivo, que não o fará mais por intermédio de uma secretaria de Ministério, mas por via de autarquia regulatória. ${ }^{14}$

14 Alexandre Aragão (2003, p. 334) comenta as relações das agências reguladoras com o Poder Legislativo em sua obra densa e consistente em doutrina. Entretanto, verificamos que a relação de entidades da Administração Federal não se compara com o papel desempenhado pelo Ministro de Estado, este sim constantemente convocado para prestar esclarecimento ao Congresso Nacional, nos termos do art. 50, Constituição Federal. 
A regulação, sob a ótica constitucional, implica em atuação de órgãos da estrutura direta do executivo e de autarquias vinculadas. Isso é o que ocorre com a interpretação do artigo 87 da Constituição Federal. Por esse dispositivo, estando a autarquia (empresa estatal ou fundação), vinculada à estrutura do Ministério ${ }^{15}$ poderá, o respectivo Ministério, anular atos ilegais, ainda que doutrina sustente o contrário.

\section{O NOVO SISTEMA DE PARTILHA DO PRÉ-SAL}

De acordo com a Lei 12.351, de 22/12/2010, o resultado da extração do óleo contido nas bacias do pré-sal atenderá a uma lógica determinada, no caso, o pagamento pelos custos operacionais e a partilha do excedente, cabendo ao parceiro o direito de comercializar esse montante.

Deve-se salientar que, após a edição desta Lei (op cit.), o regime de partilha de produção será utilizado não somente para os contratos celebrados para a exploração e a produção de petróleo em áreas do Pré-Sal, mas também poderá ser aplicado em áreas estratégicas (do ponto de vista econômico), isto é, regiões de interesse para o desenvolvimento nacional, caracterizada pelo baixo risco exploratório e elevado potencial de produção.

Em comparação com o sistema antigo, o petróleo que fosse extraído da bacia seria de domínio do concessionário, bastando apenas o pagamento da outorga, ou eventual bônus. No novo sistema, a empresa/consórcio (no caso de Libra, sob a coordenação da PETROBRAS) extrai um bem que será objeto de partilha entre União e o próprio consórcio.

A Lei 12.351/10 adota as seguintes definições (incisos selecionados):

Art. 2ำ Para os fins desta Lei, são estabelecidas as seguintes definições:

I - partilha de produção: regime de exploração e produção de petróleo, de gás natural e de outros hidrocarbonetos fluidos no qual o contratado exerce, por sua conta e risco, as atividades de exploração, avaliação, desenvolvimento e produção e, em caso de descoberta comercial, adquire o direito à apropriação do custo em óleo, do volume da produção correspondente aos royalties devidos, bem como de parcela do excedente em óleo, na proporção, condições e prazos estabelecidos em contrato;

II - excedente em óleo: parcela da produção de petróleo, de gás natural e de outros hidrocarbonetos fluidos a ser repartida entre a União e o contratado, segundo critérios definidos em contrato, resultante da diferença entre o volume total da produção e as parcelas relativas ao custo em óleo, aos royalties devidos e, quando exigível, à participação de que trata o art. 43;

III - área do pré-sal: região do subsolo formada por um prisma vertical de profundidade indeterminada, com superfície poligonal definida pelas coordenadas geográficas de seus vértices estabelecidas no Anexo desta Lei, bem como outras regiões que venham a ser delimitadas em ato do Poder Executivo, de acordo com a evolução do conhecimento geológico;

IV - operador: Petróleo Brasileiro S.A. (PETROBRAS), responsável pela condução e execução, direta ou indireta, de todas as atividades de exploração, avaliação, desenvolvimento, produção e desativação das instalações de exploração e produção; 
V - contratado: a Petrobras ou, quando for o caso, o consórcio por ela constituído com o vencedor da licitação para a exploração e produção de petróleo, de gás natural e de outros hidrocarbonetos fluidos em regime de partilha de produção.

Relatório elaborado pelo Tribunal de Contas da União (TCU) indica que ${ }^{16}$

\begin{abstract}
a justificativa para a adoção do regime de partilha para o Pré-sal está relacionada ao fato de que nessa área são estimados riscos exploratórios extremamente baixos e grandes rentabilidades, o que determina a necessidade de marco regulatório coerente com a preservação do interesse nacional, mediante maior participação nos resultados e maior controle da riqueza potencial pela União. A partilha de produção é entendida como o regime de exploração e produção de petróleo, de gás natural e de outros hidrocarbonetos fluidos no qual o contratado, em caso de descoberta comercial, adquire o direito à apropriação do custo em óleo (cost oil), do volume da produção correspondente aos royalties devidos, bem como da parcela do excedente em óleo (profit oil), na proporção, condições e prazos estabelecidos em contrato. Assim, o Estado remunera os custos de produção e divide com o contratado o excedente em óleo.
\end{abstract}

Pelo sistema licitatório adotado pela Lei $12.351 / 10$, a proposta vencedora será aquela que oferecer o maior excedente em óleo para a União, sempre tendo em vista o percentual mínimo definido previamente pelo Conselho Nacional de Política Energética (CNPE), colegiado formado pelos órgãos e entidades envolvidos na exploração e na regulação. São devidos, ainda, pelo contratado, o pagamento de bônus de assinatura devidamente fixado no edital de licitação, bem como os royalties.

Destacamos os principais pontos referentes à organização institucional do modelo de partilha:

1. A Petrobras será a operadora de todos os blocos contratados sob o regime de partilha de produção, sendo-Ihe assegurada, a este título, participação mínima no consórcio escolhido para o regime de partilha. A participação mínima da Petrobras no consórcio, previsto no art. 20, não poderá ser inferior a $30 \%$ (trinta por cento); ${ }^{17}$

2. A União não assumirá os riscos das atividades de exploração, avaliação, desenvolvimento e produção decorrentes dos contratos de partilha de produção, ${ }^{18}$ sem (de acordo com o Art. $6^{\circ}$ ): os custos e os investimentos necessários à execução do contrato de partilha de produção serão integralmente suportados pelo contratado, cabendo-lhe, no caso de descoberta comercial, a sua restituição nos termos do inciso II do art. $2^{\circ}$, correspondente aos custos e aos investimentos realizados pelo contratado na execução das atividades de exploração, avaliação, desenvolvimento, produção e desativação das instalações;

3. A gestão dos contratos previstos no caput caberá à empresa pública ${ }^{19}$ a ser criada com este propósito, $^{20}$ que não assumirá os riscos e não responderá pelos custos e investimentos referentes às atividades de exploração, avaliação, desenvolvimento, produção e desativação das instalações de exploração e produção decorrentes dos contratos de partilha de produção;

4. A Lei permite duas situações: ${ }^{21}$ a Petrobras, quando contratada diretamente ou no caso de ser vencedora isolada da licitação, deverá constituir consórcio com a empresa pública gestora dos contratos de partilha $\left(\S 1^{\circ}\right.$ do art. $\left.8^{\circ}\right)$; o licitante vencedor deverá constituir consórcio com a Petrobras e com a empresa pública gestora do contrato de partilha (Artigo 20);

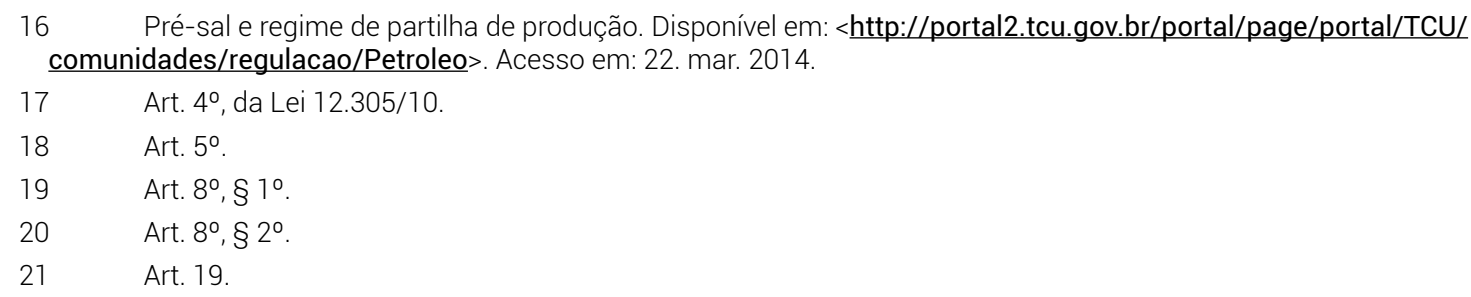


5. O contrato de constituição de consórcio ${ }^{22}$ deverá indicar a Petrobras como responsável pela execução do contrato; a empresa pública gestora ${ }^{23}$ (PPSA) do contrato de partilha integrará o consórcio como representante dos interesses da União; a administração do consórcio ${ }^{24}$ caberá ao seu comitê operacional, composto por representantes da empresa pública gestora e dos demais consorciados; a empresa pública gestora do contrato indicará a metade dos integrantes do comitê operacional, inclusive o seu presidente, cabendo aos demais consorciados a indicação dos outros integrantes;

6. Caberá ao comitê operacional, ${ }^{25}$ com a devida aprovação da ANP. a definição do plano de exploração e do plano de avaliação de descoberta de jazida de petróleo e de gás natural; a declaração de "comercialidade" (comercialização) de cada jazida descoberta, e definir o plano de desenvolvimento da produção do campo; a definição dos programas anuais de trabalho e de produção; compete também ao comitê, sem intervenção direta da ANP, analisar e aprovar os orçamentos relacionados às atividades de exploração, avaliação, desenvolvimento e produção previstas no contrato; supervisionar as operações e aprovar a contabilização dos custos realizados; e definir os termos do acordo de individualização da produção a ser firmado com o titular da área adjacente;

7. À Petrobras, na qualidade de operadora do contrato de partilha de produção, cabe: ${ }^{26}$ informar ao comitê operacional e à ANP a descoberta de qualquer jazida de petróleo, de gás natural, de outros hidrocarbonetos fluidos; submeter à aprovação do comitê operacional o plano de avaliação de descoberta de jazida de petróleo, de gás natural e de outros hidrocarbonetos fluidos, para determinação de sua comercialidade; realizar a avaliação da descoberta de jazida de petróleo e de gás natural nos termos do plano de avaliação aprovado pela ANP; submeter ao comitê operacional o plano de desenvolvimento da produção do campo, bem como os planos de trabalho e de produção, contendo cronogramas e orçamentos; adotar as melhores práticas da indústria do petróleo, obedecendo às normas e aos procedimentos técnicos e científicos pertinentes e utilizando técnicas apropriadas de recuperação, objetivando a racionalização da produção e o controle do declínio das reservas; e encaminhar ao comitê operacional todos os dados e documentos relativos às atividades realizadas.

Para a gestão dos interesses da União, na qualidade de detentora de parcela do montante em decorrência da exploração, foi instituída a "Empresa Brasileira de Administração de Petróleo e Gás Natural S.A.", também chamada "Pré-Sal Petróleo S.A." (PPSA), por intermédio da Lei 12.304, de 02/08/2010, regulamentada pelo decreto $\mathrm{n}$. 8.063, de 01/08/2013, cuja natureza é empresa pública. A empresa estatal, conforme seu art. $2^{\circ}$ : terá por objeto a gestão dos contratos de partilha de produção celebrados pelo Ministério de Minas e Energia e a gestão dos contratos para a comercialização de petróleo, de gás natural e de outros hidrocarbonetos fluidos da União.

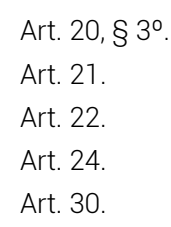


A PPSA é a entidade empresarial (de domínio estatal), gestora dos contratos celebrados sob o regime de partilha, não assumindo funções regulatórias, matéria afeta à ANP. ${ }^{27}$ A ANP, ressalte-se, continua a exercer toda a regulação e fiscalização de setor de petróleo, gás e hidrocarboneto.

Não é função da PPSA a execução, direta ou indireta, das atividades de exploração, desenvolvimento, produção e comercialização de petróleo, de gás natural e de outros hidrocarbonetos fluidos, atividade afeta ao consórcio (liderados pela PETROBRÁS). A PPSA, se verificarmos as atribuições conferidas pela Lei, é a entidade que acompanha todas as etapas da cadeira de exploração e produção, efetuando verdadeira auditoria e monitoramento sobre o processo de gestão do contrato. Além disso, no tocante ao percentual de partilha de domínio da União, a PPSA atuará na qualidade de entidade comercializadora. Dessa forma, a mesma não tem competência para explorar o serviço, não efetua qualquer trabalho operacional, mas tão somente a análise dos contratos de partilha e da exploração, para efeito de parceria, em nome da União, não possuindo qualquer competência regulatória.

A PETROBRAS será a operadora única de todos os blocos contratados sob o regime de partilha, observada a manifestação do Conselho Nacional de Política Energética (CNPE), que definirá se os blocos serão outorgados diretamente à estatal ou se serão objeto de leilão. Nesse caso, mesmo em caso de leilão, é assegurada à PETROBRAS participação mínima de $30 \%$ nos consórcios a serem constituídos com o vencedor da licitação e com a PPSA. A função da PPSA, em fase de exploração e produção, é gerenciar e fiscalizar os contratos de partilha, representando a União nos consórcios e comitês operacionais; posteriormente, a empresa fará a gestão dos contratos de comercialização de petróleo e gás natural, pertencentes à União (em virtude da partilha).

27 Art. 40 Compete à PPSA:

I- praticar todos os atos necessários à gestão dos contratos de partilha de produção celebrados pelo Ministério de Minas e Energia, especialmente:

a) representar a União nos consórcios formados para a execução dos contratos de partilha de produção;

b) defender os interesses da União nos comitês operacionais;

c) avaliar, técnica e economicamente, planos de exploração, de avaliação, de desenvolvimento e de produção de petróleo, de gás natural e de outros hidrocarbonetos fluidos, bem como fazer cumprir as exigências contratuais referentes ao conteúdo local;

d) monitorar e auditar a execução de projetos de exploração, avaliação, desenvolvimento e produção de petróleo, de gás natural e de outros hidrocarbonetos fluidos:

e) monitorar e auditar os custos e investimentos relacionados aos contratos de partilha de produção; e

f) fornecer à Agência Nacional do Petróleo, Gás Natural e Biocombustíveis (ANP) as informações necessárias às suas funções regulatórias;

II-praticar todos os atos necessários à gestão dos contratos para a comercialização de petróleo, de gás natural e de outros hidrocarbonetos fluidos da União, especialmente:

a) celebrar os contratos com agentes comercializadores, representando a União;

b) verificar o cumprimento, pelos contratados, da política de comercialização de petróleo e gás natural da União resultante de contratos de partilha de produção; e

c) monitorar e auditar as operações, os custos e os preços de venda de petróleo, de gás natural e de outros hidrocarbonetos fluidos;

III- $\quad$ analisar dados sísmicos fornecidos pela ANP e pelos contratados sob o regime de partilha de produção;

IV- $\quad$ representar a União nos procedimentos de individualização da produção e nos acordos decorrentes, nos casos em que as jazidas da área do pré-sal e das áreas estratégicas se estendam por áreas não concedidas ou não contratadas sob o regime de partilha de produção; e

V-exercer outras atividades necessárias ao cumprimento de seu objeto social, conforme definido no seu estatuto.

Parágrafo único. No desempenho das competências previstas no inciso I, a PPSA observará, nos contratos de partilha de prod ção, as melhores práticas da indústria do petróleo.

$(\ldots .$.

Art. 70 Constituem recursos da PPSA:

I- rendas provenientes da gestão dos contratos de partilha de produção, inclusive parcela que lhe for destinada do bônus de assinatura relativo aos respectivos contratos;

II-rendas provenientes da gestão dos contratos que celebrar com os agentes comercializadores de petróleo e gás natural da União; (...) 


\section{A RELAÇÃO ENTRE A PPSA E A ANP: UM NOVO SISTEMA REGULATÓRIO?}

Deve-se ter em mente que a atuação do agente regulador é um ponto, enquanto o outro é a atuação do regulado. Ambas não podem se misturar. À ANP, cabe a regulação de todo o sistema de exploração, produção, refino e transporte de petróleo, cabendo ao regulado exercer o seu efetivo papel, no caso, buscar o lucro e o desenvolvimento de novas tecnologias.

Críticas devem ser feitas à participação de dirigente da ANP no conselho da PPSA e no comitê operacional do consórcio explorador. Conforme notícia veiculada pela Empresa Brasileira de Comunicação (EBC), a Comissão de Ética da Presidência da República concluiu hoje (9 / dez. / 2013) que a diretorageral da Agência Nacional do Petróleo (ANP), Magda Chambriard, pode acumular o cargo com a função de integrante do Conselho de Administração da Empresa Brasileira de Administração de Petróleo e Gás Natural S.A., ou Pré-Sal Petróleo S.A. (PPSA), que vai gerenciar a exploração do petróleo do pré-sal ${ }^{28}$.

A participação do agente regulador na gestão do ente regulado pode gerar indícios do que se denomina "captação do regulador", comprometendo a autonomia e a eficácia do modelo regulatório. No caso, considerando que a PPSA é um representante do Poder Público, com a função inicial de auditar os contratos, há uma tendência de mútua proteção à União, com a ressalva de que voltamos ao modelo em que o então CNP funcionava como um organismo quase vinculado à PETROBRAS.

\section{CONCLUSÃO:}

Identificamos, ao longo do texto, várias questões complexas que se colocam para o futuro da exploração petrolífera no Brasil. Podemos também perceber que a discussão do atual modelo provocará consequências na regulação da atividade econômica petrolífera "pós" e "pré"-sal.

O funcionamento do mercado com excessiva participação estatal será a maneira correta de conduzir a exploração das novas descobertas do pré-sal? Nesse ponto, qual seria a distinção entre a atuação e gestão de uma empresa estatal já estruturada (PETROBRAS), na qualidade de operada do contrato, ou de um efetivo consórcio empresarial formado por todos os participantes do processo licitatório? Não seria melhor, para eficiência do sistema de partilha, a gestão compartilhada? (...) com a possibilidade de uma gestão imune à interferência do Governo central?

A definição do modelo de gestão regulatório brasileiro do petróleo é pautada na soberania, independentemente de qual estrutura empresarial estatal atuará no setor. Ao menos na exploração que se descortina, a exploração compulsória da PETROBRAS, nas reservas do pré-sal será o ideal para o mercado? (levando em conta as sucessivas interferências administrativas). Seria agora o momento de indicar as razões que nortearão a futura política regulatória para o setor?

Outro ponto que aparecerá de forma incidental é o aumento de arrecadação sobre as parcelas governamentais de compensação (royalties). $\mathrm{Na}$ atual configuração, divulga-se que os recursos destinados a estados e municípios não tem sido aplicados efetivamente em infraestrutura. Uma nova regulação deve atingir estes pontos.

\footnotetext{
$28<$ http://memoria.ebc.com.br/agenciabrasil/noticia/2013-12-09/comissao-de-etica-autoriza-diretora-da-anpocupar-cargo-na-empresa-do-pre-sal>. Acesso em: 23. mar. 2014.
} 
O uso do petróleo é questão de Estado ${ }^{29}$ e não uma visão restrita de Governo ${ }^{30}$. Um novo modelo deve proporcionar ou fazer surgir uma cultura regulatória tutelada por políticas e estratégias centradas nas necessidades do Estado e da economia, de maneira planejada, em que o Governo procura adequar projetos e programas com maior economicidade e eficiência.

Mesmo pensando em Estado, fica difícil, no Brasil, o Estado não ser "capturado" por governos (e partidos políticos). "Uma recente estimativa feita pelo banco americano Morgan Stanley, com base em informações obtidas com delação premiada de ex-diretores da estatal, os desvios na PETROBRAS podem chegar a 21 bilhões de reais" (Pinheiro, 2015, p. 22).

Outra importante questão é a do preço do petróleo no mercado internacional. "Com a queda acentuada do barril de petróleo, que baixou de cerca de US\$100 em junho de 2014 para menos de US\$ 45" na primeira quinzena de janeiro de 2015, "a PETROBRAS vê seu mais importante projeto balançar sobre uma linha tênue", pois pesquisadores calculam que "o preço mínimo do sucesso [para o pré-sal] é de US\$ 65" (Kroehn, 2015).

Fechamos o texto com uma pergunta: não seria melhor para a indústria dos energéticos, e para os consumidores brasileiros, sair do regime de "partilha" e passar para o regime de "concessão"?

\section{REFERÊNCIAS}

AGENCIA BRASIL/EBC. Comissão de Ética autoriza diretora da ANP a ocupar cargo na empresa do pré-sal. Disponível em <http://memoria.ebc.com.br/agenciabrasil/noticia/2013-12-09/comissaode-etica-autoriza-diretora-da-anp-ocupar-cargo-na-empresa-do-pre-sal> Acesso em 23.mar.2014.

ALVEAL, Carmen . "Estado e Regulação Econômica: o papel das agências reguladoras no Brasil e na experiência internacional", Seminário de Direito Internacional e Regulação Econômica. Ministério Público da União - Núcleo Regional do Rio de Janeiro (texto da Conferência; 19 e 20 de maio de 2003; 19 páginas).

ARAGÃO, Alexandre. Agências reguladoras. Rio de Janeiro: Forense, 2003.

DI PIETRO, Maria Sylvia Zanella. Direito administrativo. 19a ed. São Paulo: Atlas, 2006.

DUTRA, Pedro Paulo Almeida. Controle de empresas estatais: uma proposta de mudança. São Paulo: Saraiva, 1991.

GASPAR, Malu \& TEIXEIRA Jr., Sérgio. "A Riqueza do Fundo do Mar", Revista Exame, 27 de agosto de 2008.

HEGENBERG, Flavio E. Novaes "Environmental Management and the Equipment \& Technology Market: business implications for mining \& metallurgy in a globalised and environmentally problematic age" (p. 96-124), In: Villas-Bôas, Roberto C; Fellows-Filho, Lélio (coord.) Technological Challenge Posed by Sustainable Development: the mineral extraction industries. Madrid (Spain): Ciencia y Tecnologia para el Desarrollo - CYTED, 2000.

\footnotetext{
29 Da Nação, considerando o longo prazo (horizontes maiores do que 20 anos).

30 Dos agentes políticos temporários que ocupam postos de controle no âmbito do Estado; considerando prazos curtos ou médios (referentes aos períodos de meses ou anos quando tais agentes ocupam posições de governo).
} 
KROEHN, Márcio "Quando o petróleo será nosso?" (página 66), Dinheiro, 21 de janeiro de 2015.

SOUTO, Marcos Juruena Villela. Direito administrativo da economia. Rio de Janeiro: Forense, 2003.

Direito administrativo das parcerias. Rio de Janeiro: Forense, 2005.

MEDAUAR, Odete. 0 direito administrativo em evolução. 2a ed. São Paulo: Revista dos Tribunais, 2003.

MUSACCHIO, Aldo \& LAZZARINI, Sergio G. Reinventando o Capitalismo de Estado: o Leviatã nos negócios, Brasil e outros países. São Paulo: Portfolio Penguin, 2015 [Tradução de Afonso Celso da Cunha Serra de "Reinventing State Capitalism: Leviathan in Business, Brazil and Beyond", publicado em 2014 pela Harvard University Press].

NUSDEO, Fábio. Fundamentos para uma codificação do direito econômico. São Paulo: Revistas dos Tribunais, 1995.

PINHEIRO, Daniela "Outra História Americana: como a PETROBRAS negociou pagar quase seis vezes mais por uma área de exploração de petróleo e gás nos Estados Unidos" (páginas 18-23), Piauí, março de 2015.

PRATES, Jean-Paul "Petrobras, pré-sal e futuro", Le Monde Diplomatique Brasil, Ano 8, número 92, março de 2015, página 5.

STRAUSS, Peter (et al.) Direito e regulação no Brasil e nos EUA. STRAUSS, Peter. Órgãos do sistema federal americano. São Paulo: Malheiros Editores, 2004a.

STRAUSS, Peter (et al.) Direito e regulação no Brasil e nos EUA. STRAUSS, Peter. Controles políticos e legais. São Paulo: Malheiros Editores, 2004b.

SUNFELD, Carlos Ary. Direito administrativo econômico. SUNFELD. Carlos Ary. Regime jurídico do setor petrolífero. São Paulo: Malheiros, 2002.

TRIBUNAL DE CONTAS DA UNIÃO. Regulação e regime de partilha de produção. Disponível em <http:// portal2.tcu.gov.br/portal/page/portal/TCU/comunidades/regulacao/Petroleo>Acesso em 20.mar.2014. 